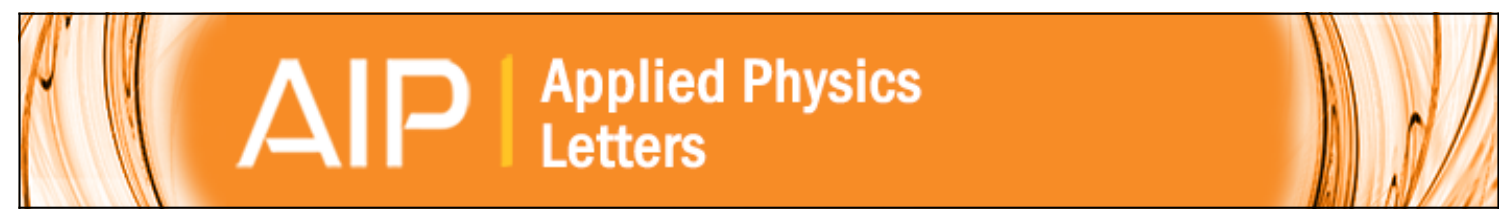

\title{
Ion beam synthesis of cubic FeSi2
}

J. Desimoni, H. Bernas, M. Behar, X. W. Lin, J. Washburn, and Z. Liliental-Weber

Citation: Applied Physics Letters 62, 306 (1993); doi: 10.1063/1.108969

View online: http://dx.doi.org/10.1063/1.108969

View Table of Contents: http://scitation.aip.org/content/aip/journal/apl/62/3?ver=pdfcov

Published by the AIP Publishing

\section{Articles you may be interested in}

Endotaxially stabilized B2-FeSi nanodots in Si (100) via ion beam co-sputtering

Appl. Phys. Lett. 104, 161903 (2014); 10.1063/1.4872315

Photoreflectance study of ion beam synthesized $\beta$ - FeSi 2

J. Appl. Phys. 91, 1219 (2002); 10.1063/1.1428792

Raman investigation of ion beam synthesized $\beta$ - FeSi 2

J. Appl. Phys. 89, 965 (2001); 10.1063/1.1326473

Metastable y phase in ion beam synthesized FeSi2

Appl. Phys. Lett. 68, 1784 (1996); 10.1063/1.116666

Low-temperature ion-induced epitaxial growth of $\alpha-\mathrm{FeSi} 2$ and cubic FeSi2 in $\mathrm{Si}$

Appl. Phys. Lett. 63, 105 (1993); 10.1063/1.109727

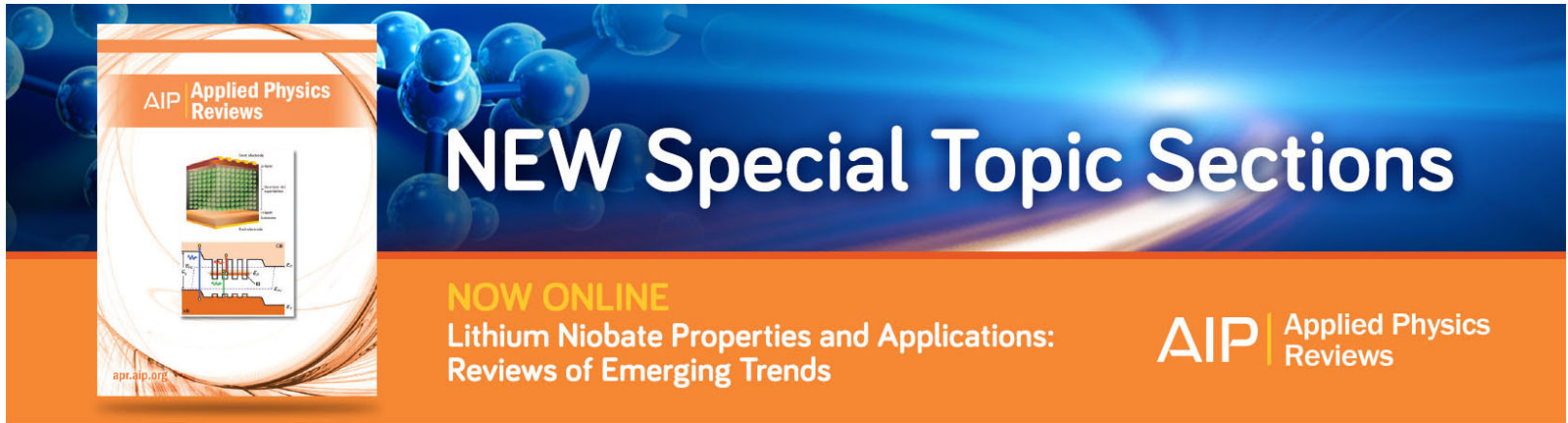




\title{
Ion beam synthesis of cubic $\mathrm{FeSi}_{2}$
}

\author{
J. Desimoni, ${ }^{\text {a) }}$ H. Bernas, and M. Behar ${ }^{\text {) }}$ \\ Centre de Spectrométrie Nucléaire et Spectrométrie de Masse, Bât. 108, 91405 Orsay Campūus, France
}

X. W. Lin, J. Washburn, and Z. Liliental-Weber

Lawrence Berkeley Laboratory, Berkeley, California 94720

(Received 20 May 1992; accepted for publication 28 October 1992)

Cubic $\mathrm{FeSi}_{2}$ precipitates were synthesized in $\mathrm{Si}(100)$ by room-temperature $\mathrm{Fe}$ ion implantation followed by $\mathrm{Si} 500 \mathrm{keV}$ ion beam induced epitaxial crystallization at $320^{\circ} \mathrm{C}$. High resolution electron microscopy and Rutherford backscattering/channeling techniques show that the cubic precipitates occur in both aligned (A) and twinned (B) types with a lattice parameter very similar to that of the $\mathrm{Si}(100)$ matrix.

Because of possible applications in silicon technology, considerable work has been performed in recent years on the synthesis and propertics of iron disilicide. The two known stable phases $^{1-3}$ are the tetragonal (metallic) $\alpha-\mathrm{FeSi}_{2}$ phase, and the orthorhombic (semiconducting) $\beta-\mathrm{FeSi}_{2}$, which grows epitaxially on $\mathrm{Si}(111)$ and is stable up to $940^{\circ} \mathrm{C}$. Recently a metastable (metallic ${ }^{4}$ ) cubic $\mathrm{FeSi}_{2}$ phase, with a lattice parameter similar to that of $\mathrm{Si}$, was obtained by different forms of solid phase epitaxy ${ }^{4,5}$ at temperatures below $400^{\circ} \mathrm{C}$ on a $\mathrm{Si}$ (111) substrate. This phase converts to $\beta-\mathrm{FeSi}_{2}$ when the layer thickness exceeds a critical value (typically $0.6-30 \mathrm{~nm}$ ).

Since the cubic phase is metastable, the possibility of forming it by nonequilibrium techniques such as pulsed laser annealing or ion beam treatments warrants study. Pulsed laser irradiation of an SPE $\beta-\mathrm{FeSi}_{2}$ layer grown on a $\mathrm{Si}$ (111) substrate ${ }^{6}$ produced a $30 \mathrm{~nm}$ thick cubic phase epitaxial layer in B-type (twinned). The aim of the present work was to determine whether it is possible to form cubic $\mathrm{FeSi}_{2}$ using $\mathrm{Fe}$ implantation and subsequent ion beam induced epitaxial crystallization (IBIEC) of the Si host. Wc show that isolated epitaxial cubic $\mathrm{FeSi}_{2}$ precipitates can be formed in this way.

$\mathrm{Si}(100)$ wafers (p-type, $1 \Omega \mathrm{cm}$ ) were roomtemperature implanted with $\mathrm{Fe}$ at energies between 50 and $180 \mathrm{keV}$ and fluences between $1 \times 10^{16}$ and $4 \times 10^{16}$ $\mathrm{Fe} \mathrm{cm}{ }^{-2}$ (corresponding to peak $\mathrm{Fe}$ concentrations between ca. 4-7 at. \%). Implantation current densities were below $1 \mu \mathrm{A} \mathrm{cm}^{-2}$ in order to minimize sample heating. Channeled implantation was avoided by tilting samples by $7^{\circ}$ with respect to the ion beam. IBIEC was carried out at $320^{\circ} \mathrm{C}$ with the ARAMIS high-energy implanter ${ }^{8}$ using a $500 \mathrm{keV} \mathrm{Si}$ beam (current density ca. $1 \mu \mathrm{A} \mathrm{cm}{ }^{2}$, total fluences between $4 \times 10^{16}$ and $1 \times 10^{17} \mathrm{Si} \mathrm{cm}^{-2}$ ). The samples were analyzed in situ by Rutherford backscattering and channeling (RBS/C) at $165^{\circ}$ scattering angle using 1.2 $\mathrm{MeV} \mathrm{He}$ ions. The near-surface $\mathrm{Fe}$ distribution was studied by RBS at a scattering angle of $83^{\circ}$. Transmission electron microscopy (TEM), selected area diffraction (SAD), and high resolution electron microscopy (HREM) were per-

\footnotetext{
${ }^{a)}$ On leave from Departamento de Fisica, Facultad de Ciencias Exactas, U.N.L.P., under a fellowship of CONICET, Argentina.

b) On leave from Instituto de Fisica, U.F.R.G.S. Porto Alegre, Brazil.
}

formed at Lawrence Berkeley Laboratory.

Figure 1 displays the random and channeled RBS spectra of a sample implanted at $50 \mathrm{keV}$ with $1 \times 10^{16}$ $\mathrm{Fe} \mathrm{cm}{ }^{-2}$. The Si wafer was amorphized over $100 \mathrm{~nm}$. Figure 2 shows that after the subsequent $500 \mathrm{keV}$ Si irradiation at $320^{\circ} \mathrm{C}$, the entire amorphous layer was recrystallized, the minimum backscattering yield on subsurface $\mathrm{Si}$ being $\chi_{\min }=0.12$. Some channeling was observed in the Fe part of the spectrum $\left(\chi_{\min }=0.73\right)$. The corresponding grazing RBS experiment (not shown here) showed that about $10 \%$ of the implanted $\mathrm{Fe}$ atoms were transported to the surface as a consequence of the IBIEC process.

Shown in Fig. 3(a) is a TEM bright-field image of an IBIEC-processed sample viewed along Si [110]. This sample was implanted at two different energies (180 and 100 $\mathrm{keV}$ ) in order to obtain a reasonably uniform Fe concentration of 7 at. \%. It displays a layered structure with (i) a $150 \mathrm{~nm}$ thick layer just below the surface, (ii) a darkcontrasted layer, $600 \mathrm{~nm}$ thick, sandwiched between the latter, and (iii) a relatively unperturbed $\mathrm{Si}$. The middle of the dark contrasted layer corresponds to the projected range of $500 \mathrm{keV} \mathrm{Si}\left(R_{p}=750 \mathrm{~nm}\right)$. In spite of the

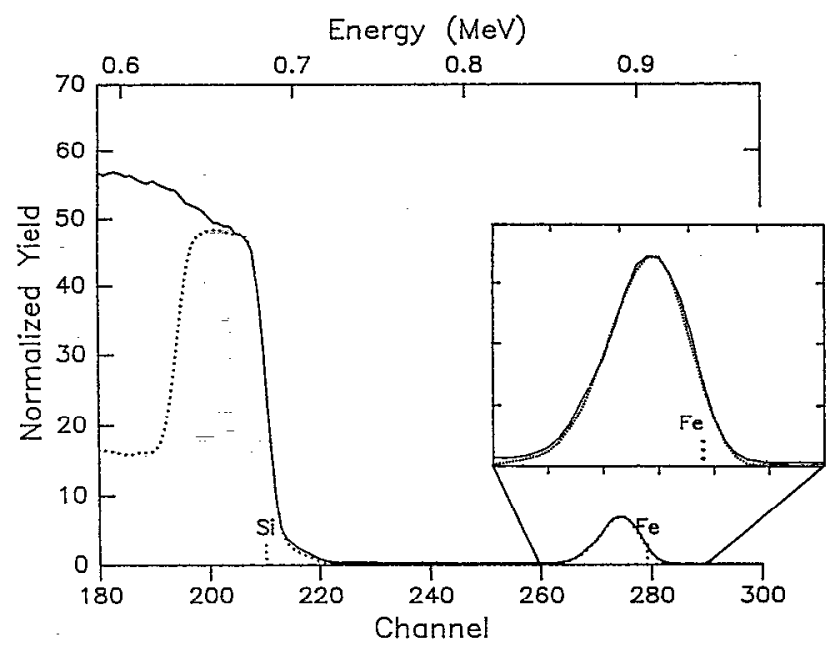

FIG. 1. Random (full line) and [100] channeled RBS spectra (dots) of a $\mathrm{Si}(100)$ sample implanted with $50 \mathrm{keV} \mathrm{Fe}$ at a fluence of $1 \times 10^{16}$ at $\mathrm{cm}^{-2}$. The amorphous layer is $100 \mathrm{~nm}$ thick. The inset shows the random and channeling spectra corresponding to the $\mathrm{Fe}$ profile. 


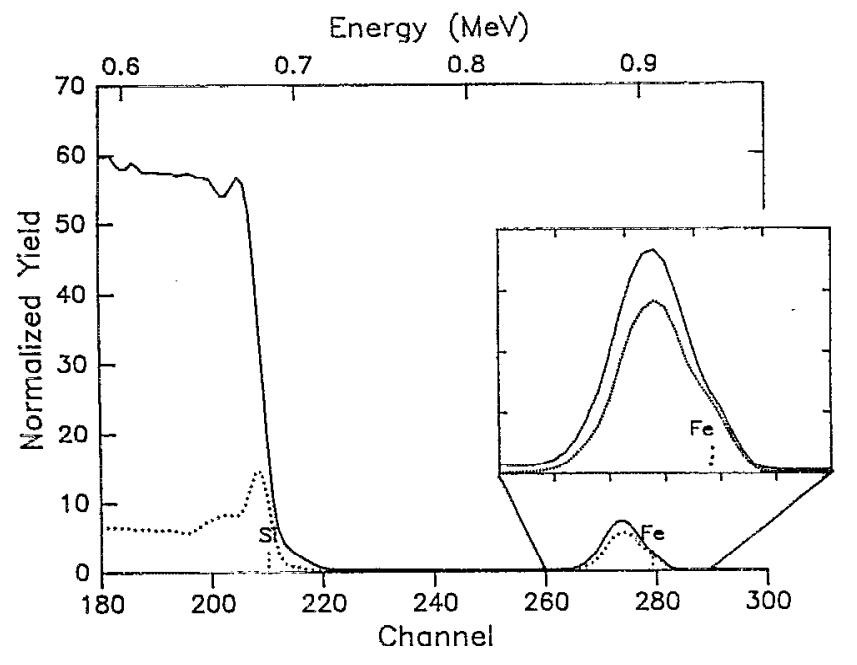

FIG. 2. Random (full line) and channeled RBS spectra (dots) of the same sample displayed in Fig. 1, after a $4 \times 10^{16}$ at $\mathrm{cm}^{-2} \mathrm{Si}$ irradiation at $320^{\circ} \mathrm{C}$. The $\mathrm{Fe}$ profile shows a partial degree of alignment-see insetand $\mathrm{Si}$ substrate has completely recrystallized.

irradiation-induced damage, the structure of this layer remains crystalline, as indicated by its SAD pattern [Fig. 3 (c)] which corresponds to the $\mathrm{Si}$ [110] zone axis.

Figure $3(\mathrm{~b})$ is a SAD pattern taken from the surface layer where the most intense spots are indexed as reflections from the Si [110] zone axis. A regular array of weak spots is superimposed on the $\mathrm{Si}$ spots. These spots can be interpreted as reflections from a cubic $\mathrm{FeSi}_{2}$ phase whose lattice parameter is almost identical to that of the Si matrix. Figure 4 shows HREM images of near-surface $\mathrm{FeSi}_{2}$ precipitates with a diameter ca. $5 \mathrm{~nm}$. Two types of $\mathrm{FeSi}_{2}$ precipitates can be recognized. Type A [Fig. 4(c)], corre-

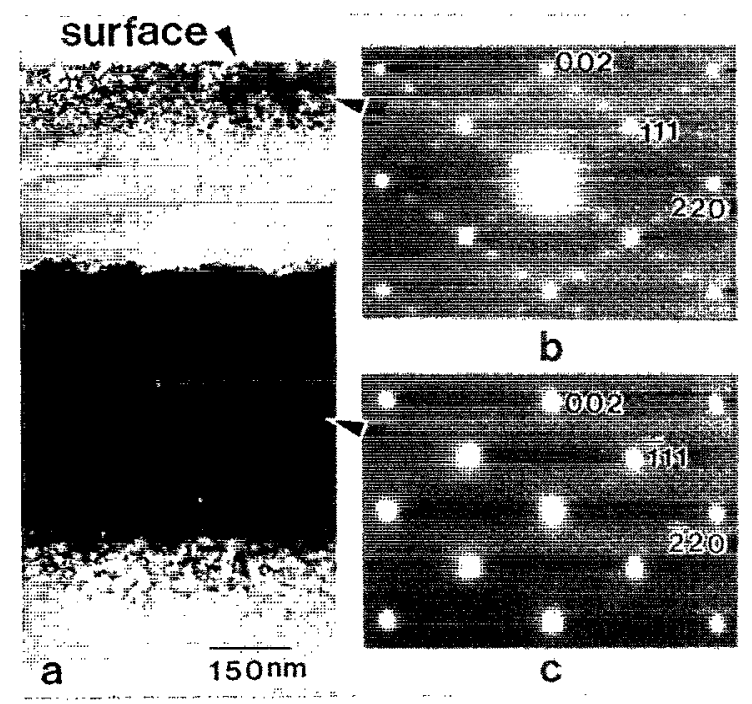

FIG. 3. (a) A TEM micrograph showing the cross section of an IBIECprocessed Fe-implanted Si. (b) An SAD pattern taken from the surface layer. The most intense spots are indexed as reflections from the $\mathrm{Si}$ [100] zone axis and the weak ones are due to the $\mathrm{B}$-type cubic $\mathrm{FeSi}_{2}$ precipitates [see Fig. 4(b)] combined with the double diffraction effect. (c) A SAD pattern from dark-contrasted layer showing reflections from the $\mathrm{Si}$ [100] zone axis.

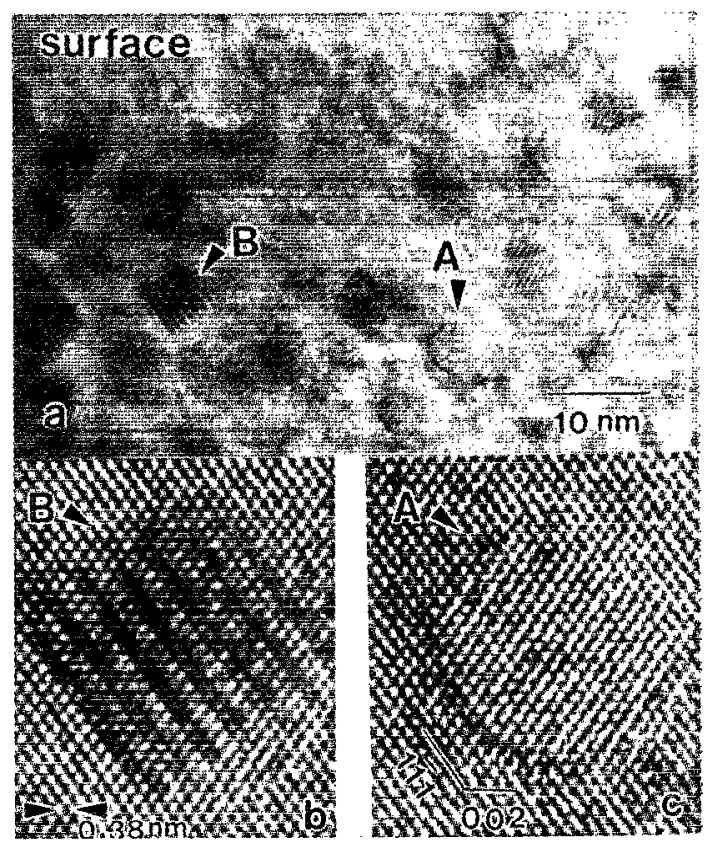

FIG. 4. (a) An HREM image of the surface layer viewed along Si [100]. Arows $A$ and $B$ indicate two types of precipitates that are formed epitaxially in the Si matrix. (b) An HREM image of a B-type precipitate seen at a higher magnification. (c) An HREM image of an A-type precipitate seen at a higher magnification.

sponds to precipitates formed epitaxially in the Si matrix with a fully aligned orientation relationship to the Si matrix. Type B [Fig. 4(b)] corresponds to precipitates that are rotated $180^{\circ}$ about [111] of Type A, i.e., twinned relative to Type A. Thus, the weak spots in Fig. 3(b) are due to reflections from the B-type precipitates, together with the double diffraction effect, whereas the reflections from the A-type $\mathrm{FeSi}_{2}$ precipitates cannot be seen in Fig. 3(b) because they overlap with the spots of the $\mathrm{Si}[110]$ zone axis.

Note that in previous work ${ }^{5,6}$ only B-type orientation was observed, whereas here both A- and B-type precipitates occur. Preliminary results show that decreasing the $\mathrm{Fe}$ concentration increases the proportion of A-type. Finally, in Ref. 6 the stability of the continuous cubic $\mathrm{FeSi}_{2}$ layer was checked up to $300^{\circ} \mathrm{C}$; post-irradiation vacuum furnace annealing performed at $520^{\circ} \mathrm{C}$ did not affect the structure of the cubic phase precipitates in our case.

To our knowledge, this is the first report that aligned cubic $\mathrm{FeSi}_{2}$ precipitates can be formed by an ion beam technique.

The technical support of the Semiramis Group at Orsay is acknowledged, as well as W. Swider for help in TEM specimen preparation. Discussions with J. Derrien and J. Chevrier were essential. The microscopy was performed with the facilities of the National Center for Electron Microscopy funded by the U.S. Department of Energy under Contract No. DE-AC03-76SF00098.

${ }^{1}$ J. E. Mahan, K. M. Geib, G. Y. Robinson, R. G. I.ong, Y. Xinghua, G. Bai, M. A. Nicolet, and M. Nathan, Appl. Phys. Lett. 56, 2126 (1990).

${ }^{2}$ K. Rademacher, S. Mantl, Ch. Dicker, and H. Luth, Appl. Phys. Lett. 59, 2145 (1991).

${ }^{3}$ D. J. Oostra, D. E. W. Vandenhoudt, C. W. T. Bulle-Lieuwma, and E. 
P. Naburgh, Appl. Phys. Lett. 59, 1737 (1991).

${ }^{4}$ J. Chevrier, V. Le Than, S. Nitzche, and J. Derrien, Appl. Surf. Sci. 56-58, 438 (1992); V. Le Than, J. Chevrier, and J. Derrien, Phys. Rev. $B$ (to be published).

${ }^{5}$ N. Onda, J. Henz, E. Muller, K. A. Mader, and H. von Kanel, Appl. Surf. Sci. 56-58, 421 (1992).
${ }^{6}$ M. G. Grimaldi, P. Baeri, C. Spinella, and S. Lagomarsino, Appl. Phys. Lett. 60, 1132 (1992).

${ }^{7}$ F. Priolo and E. Rimini, Mater. Sci. Rep. 5, 319 (1990).

${ }^{8}$ H. Bernas, J. Chaumont, E. Cottereau, R. Meunier, A. Traverse, C. Clerc, O. Kaitasov, F. Lalu, D. Le Du, G. Moroy, and M. Salomé, Nucl. Instrum. Methods 62, 416 (1992). 